OPEN ACCESS

Edited by:

Nurit Hollander,

Tel Aviv University, Israel

Reviewed by:

Ji Ming Wang,

National Cancer Institute at Frederick,

USA

Pedro Berraondo, Centro de Investigación Médica Aplicada, Spain

*Correspondence:

Karine Breckpot

kbreckpo@vub.ac.be

Specialty section:

This article was submitted to Immunotherapies and Vaccines,

a section of the journal

Frontiers in Immunology

Received: 22 January 2016

Accepted: 14 March 2016

Published: 29 March 2016

Citation:

De Vlaeminck Y, González-Rascón A,

Goyvaerts C and Breckpot K (2016)

Cancer-Associated Myeloid

Regulatory Cells.

Front. Immunol. 7:113.

doi: 10.3389/fimmu.2016.00113

\section{Cancer-Associated Myeloid Regulatory Cells}

\author{
Yannick De Vlaeminck ${ }^{1}$, Anna González-Rascón ${ }^{1,2}$, Cleo Goyvaerts ${ }^{1}$ and Karine Breckpot ${ }^{1 *}$ \\ ${ }^{1}$ Laboratory of Molecular and Cellular Therapy, Department of Biomedical Sciences, Vrije Universiteit Brussel, Brussels, \\ Belgium, ${ }^{2}$ Centro de Investigación en Alimentación y Desarrollo, Hermosillo, Mexico
}

Myeloid cells are critically involved in the pathophysiology of cancers. In the tumor microenvironment (TME), they comprise tumor-associated macrophages (TAMs), neutrophils (TANs), dendritic cells, and myeloid-derived suppressor cells, which are further subdivided into a monocytic subset and a granulocytic subset. Some of these myeloid cells, in particular TAMs and TANs, are divided into type 1 or type 2 cells, according to the paradigm of $T$ helper type 1 or type 2 cells. Type 1 -activated cells are generally characterized as cells that aid tumor rejection, while all other myeloid cells are shown to favor tumor progression. Moreover, these cells are often at the basis of resistance to various therapies. Much research has been devoted to study the biology of myeloid cells. This endeavor has proven to be challenging, as the markers used to categorize myeloid cells in the TME are not restricted to particular subsets. Also from a functional and metabolic point of view, myeloid cells share many features. Finally, myeloid cells are endowed with a certain level of plasticity, which further complicates studying them outside their environment. In this article, we challenge the exclusive use of cell markers to unambiguously identify myeloid cell subsets in the TME. We further propose to divide myeloid cells into myeloid regulatory or stimulatory cells according to their pro- or antitumor function, because we contend that for therapeutic purposes it is not targeting the cell subsets but rather targeting their protumor traits; hence, myeloid regulatory cells will push antitumor immunotherapy to the next level.

\section{Keywords: cancer, tumor microenvironment, myeloid cells, monocyte, macrophage, dendritic cell, neutrophil,} myeloid-derived suppressor cell

\section{INTRODUCTION}

The immune system's role in malignancies appears to be more complex than originally anticipated (1-5). Several immune mechanisms can support antitumor immunity; however, they are often counteracted due to immunosuppressive mechanisms exerted by the tumor and its environment (6). For many cancers, including ovarian, renal cell, colorectal, and breast cancer, prognosis, metastatic burden, and therapeutic response rates have been linked to immune cell populations that infiltrate the tumor (7-10). Consequently, the focus in antitumor immunotherapy started to shift from exclusive stimulation of innate and adaptive immunity to combinations with intratumoral modifications (11).

The tumor microenvironment (TME) comprises a complex milieu of non-malignant cells, such as cells from endothelial, mesenchymal, and immunological origin (5). Among the tumor-infiltrating immune cells, myeloid cells represent a prominent component both in terms of quantity and function (12-14). They consist of a heterogeneous mixture of monocytes, tumor-associated granulocytes 
(mainly neutrophils or TANs), myeloid-derived suppressor cells (MDSCs), tumor-associated macrophages (TAMs), and tumorassociated dendritic cells (TADCs). To complicate matters, these different cell types are characterized by different polarization states with both stimulatory and tolerogenic functions, often referred to as type 1 and type 2 states, respectively. It is well described that mature TADCs, type 1 TAMs and TANs can counteract tumor growth by stimulating T-cell-mediated antitumor immunity (15). By contrast, type 2 TAMs and TANs, immature TADCs, a subset of mast cells and MDSCs mainly promote tumor progression via immunosuppression, stimulation of angiogenesis, and secretion of growth factors. Consequently tumor-infiltrating myeloid cells are critical contributors to the "never-healing-wound" that characterizes most solid tumors and as such they are an attractive target for novel therapies (16-20). However, interpreting relevant literature is currently challenging since the same cell type is often given another name based on the use of the so-called "unique" markers and functions. In reality, these markers and functions are shared between different cell types as they are driven by tumorderived factors that trigger transcriptional programs and as such determine the cell's phenotype and activity.

\section{IDENTITY CRISIS}

Under physiological conditions, myeloid cells can be distinguished by their ontogenic transcription factors. Monocytes, macrophages, and DCs are derived from the monocyte/macrophage and DC precursor, while granulocytes originate from the granulocyte precursor. Both precursors arise from the granulocyte/macrophage progenitor, which in turn is derived from the common myeloid progenitor stemming from the hematopoietic stem cell (21-23).

Myeloid cells arising in cancer patients fail to display normal features of myeloid differentiation resulting in atypical myelopoiesis in the bone marrow, periphery, and within the TME (10). In general, modulatory signals originating from the TME, such as transforming growth factor (TGF)- $\beta$, colonystimulating factor-1 (CSF-1), CSF-2, and various others, induce the attraction and expansion of bone marrow and blood-derived immature myeloid cells. Once in the tumor, they are classified as monocytes, TAMs, MDSCs, TADCs, and TANs, based on their surface marker expression, which can differ depending on the tumor type, the location within the tumor as well as the stage of tumor progression (24). Consequently, markers that are often used to distinguish murine myeloid cell subsets, such as CD11c, F4/80, CD11b, and Gr1, appear to be shared among subsets as illustrated in Figure 1.

Perhaps one of the most striking examples of shared markers that are often used to define myeloid cell subsets is the expression of the prototypical DC and macrophage markers CD11c and F4/80, which are both expressed by TADCs and TAMs $(15,25,26)$. The same holds true for human tumor-infiltrating myeloid cells,

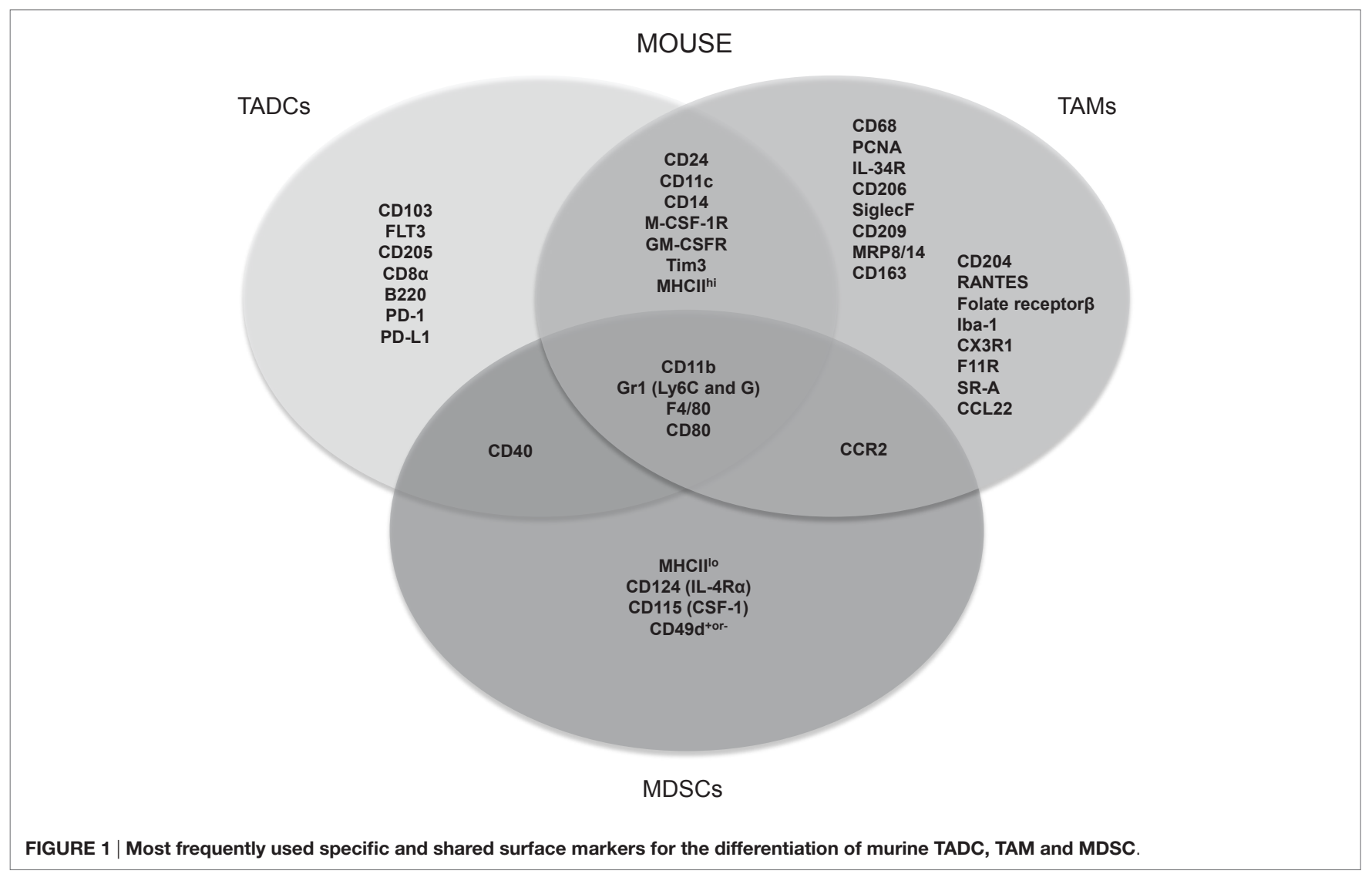


as, for example, human TAMs are often characterized by CD68, a receptor that is also expressed by other stromal tumor populations (27). It is clear that myeloid cells within the TME are not only hard to distinguish from each other but they can moreover trans-differentiate into one another. In the case of MDSCs, for example, it has been shown that they could trans-differentiate into macrophages, granulocytes, or DCs (28-35). Furthermore, it was also suggested that TADCs can converse into morphological, phenotypical, and functional TAMs (36). However, we must be careful to draw decisive conclusions from this study as they made use of CD11c, CD11b, and F4/80 as discriminating phenotypic markers. As mentioned above, these are expressed on both TAMs and TADCs, albeit at different levels.

The above examples suggest that it seems more appropriate to state that the formerly applied terms to characterize tumorinfiltrating myeloid cell subpopulations represent extremes of a continuum in a universe of activation states, including classically and alternatively activated immature, mature, type 1 and type 2 tumor-infiltrating myeloid cells $(37,38)$.

\section{THE TYPE 1/TYPE 2 PARADIGM}

Although myeloid cells can be subdivided based on specific ontogenic, functional, and phenotypic features, they are all subjected to the same "ground rules" present within the TME in a stratified way (39). This results in the adoption of two main polarization states that mirror the $\mathrm{T}$ helper $1 / 2$ paradigm of $\mathrm{CD} 4^{+} \mathrm{T}$ cells.

Myeloid cells with a type 1 phenotype function as inflammatory, tissue (matrix)-destructive and immune-stimulating cells. These cells perform their immune stimulatory function by secretion of pro-inflammatory cytokines, such as tumor necrosis factor (TNF)- $\alpha$, interleukin-1 (IL-1), IL-6, and IL-12 combined with a strong capacity to process and present tumor antigens. Furthermore, they are able to kill tumor cells by the production of inducible nitric oxide synthase (iNOS) (40). These functions are metabolically supported by increased glycolysis and pentose phosphate pathway, which provide rapid ATP production and biosynthetic intermediates required for the generation of pro-inflammatory proteins (41, 42). Alternatively activated type 2 tumor-infiltrating myeloid cells are characterized as cells mediating tissue repair and immune suppression. To exert their suppressive function, type 2 tumor-infiltrating myeloid cells secrete among others IL-10 and TGF- $\beta$, and express enzymes, such as arginase- 1 and indoleamine 2,3-dioxygenase (IDO), which deplete the TME from nutrients essential for T cells. Moreover, type 2 tumor-infiltrating myeloid cells produce factors involved in tissue repair and angiogenesis, such as vascular endothelial growth factor (VEGF) (43). Finally, they tend to rely on oxidative phosphorylation, which is important for their long-term activation and subsequent return to homeostasis (41).

In the case of TANs and TAMs, this is reflected in the N1/ $\mathrm{N} 2$ and M1/M2 paradigm. Of note, it is described that TAMs have a transcriptional profile distinct from the classically activated M1 or alternatively activated M2 macrophages found under tumor-free steady-state conditions. However, due to a certain "overlap" of transcriptional molecules present in the classically and alternatively activated macrophages and the TAMs, it has been suggested that TAMs can adapt an M1, M2, or shared M1/M2 signature (44). For example, human TAMs co-expressing HLA-DR, a typical M1 marker as well as CD163, a typical M2 marker have been observed as well; again reflecting that also the type 1/type 2 paradigm reflects two extremes of a continuum $(45,46)$. Likewise, TADCs and MDSCs seem to preserve their original division. Tumor-associated DCs, similar to peripheral DCs, are subdivided into plasmacytoid DCs (pDC), two conventional DC subsets (cDC1 and cDC2), and monocyte-derived DCs (47). MDSCs are subdivided into a monocytic subset and a granulocytic subset. While MDSCs are intrinsically characterized by suppressive type 2 functions, TADCs can display Janus-like features. When activated, they can initiate potent tumor antigen-specific immune responses. However, when immature, they contribute to genomic damage, angiogenesis, stimulation of tumor cell growth, and spreading. Moreover, immature TADCs induce antigen-specific T-cell unresponsiveness through direct and indirect mechanisms (48). The knowledge that TADCs present tumor antigenderived peptides, however, fail to provide co-stimulation has instigated attempts to activate TADCs for immunotherapeutic purposes (49). Indeed, targeted delivery of DC potentiating stimuli, as exemplified by the delivery of TriMix mRNA, enables TADCs to migrate to draining lymph nodes and activate tumor antigen-specific $\mathrm{T}$ cells, which in turn migrate to the tumor to mediate tumor cell rejection (50).

It has been suggested to redefine MDSCs as "myeloid regulatory cells" based on their ability to suppress host antitumor immunity (51). However, since their functional, metabolic, and phenotypic features are not unique to MDSCs but shared between the suppressive "type 2" myeloid cells, we question the confinement of the term myeloid regulatory cells to MDSCs (52). In accordance with the type 1/type 2 paradigm, we propose to redevise tumor-infiltrating myeloid cells into tumoricidal myeloid stimulatory and tumor-promoting myeloid regulatory cells. Myeloid stimulatory cells would include polarization states with an $\mathrm{M} 1$, mature TADC, and N1 phenotype, while myeloid regulatory cells would include their type 2 counterparts: M2, immature TADCs, and N2, respectively, together with the monocytic and granulocytic MDSCs. Different tumor-infiltrating myeloid cell subsets amplify tolerance by cross-talk with each other and other stromal cells from the TME. For example, MDSCs induce type 2 TAMs via IL-10, which in turn enhance the IL-10 production by MDSCs, resulting in a positive feedback mechanism for sustained type 2 TAM generation (53). The myeloid regulatory cells and myeloid stimulatory cells represent a classification system based on shared functional hallmarks that result from common intratumoral incentives.

The functional skewing of myeloid cell populations in antitumor or myeloid stimulatory cells, and protumor or myeloid regulatory cells is possible due to myeloid cell plasticity. Myeloid cells adapt to environmental signals, which govern their transcriptional profile and consequently their phenotypical and functional traits. It is becoming clear that transcriptional pathways promoting polarized functions of different myeloid cell subsets share common constituents. Key signaling networks cooperate, 
TABLE 1 | Overview of strategies studied to manipulate murine and human tumor-infiltrating myeloid cells.

\begin{tabular}{|c|c|c|c|c|}
\hline Target & Moiety & Cancer model & Effect & Reference \\
\hline \multicolumn{5}{|c|}{ Tumor-infiltrating myeloid cell-related receptors } \\
\hline \multirow[t]{2}{*}{$\begin{array}{l}\text { CSF-1R/CSF-1 } \\
\text { signaling }\end{array}$} & $\begin{array}{l}\text { Small molecules, monoclonal Ab, } \\
\text { siRNA }\end{array}$ & $\begin{array}{l}\text { Mouse (melanoma, glioblastoma, breast, } \\
\text { pancreas, and colorectal cancer) }\end{array}$ & $\begin{array}{l}\downarrow T A M, \text { Mo-MDSC recruitment } \\
\text { TAM, M-DCs depletion } \\
\uparrow T A M \text { repolarization }\end{array}$ & $(25,56-61)$ \\
\hline & & $\begin{array}{l}\text { Human (neuro- and glioblastoma, giant cell } \\
\text { tumor, and lung cancer) }\end{array}$ & $\begin{array}{l}\downarrow \text { TAM recruitment } \\
\downarrow \text { CD14 dim/CD16+ monocytes in plasma } \\
\text { TAM depletion }\end{array}$ & $(62-66)$ \\
\hline CCL2/MCP-1 & Small molecules and monoclonal Ab & Human (melanoma and prostate cancer) & $\downarrow T A M$ recruitment & $(67)$ \\
\hline CD11b & Monoclonal Ab & Mouse (ovarian cancer) & TAM, TADC, and MDSC depletion & $(68)$ \\
\hline IL12R/IL18R & Adenovirus & Mouse (sarcoma) & $\uparrow T A D C$ repolarization & $(69)$ \\
\hline \multirow[t]{2}{*}{ CD40 } & Monoclonal Ab & Mouse (bladder cancer) & $\uparrow D C$ activation & $(70)$ \\
\hline & & Human (several cancers) & $\uparrow D C$ maturation & $(71)$ \\
\hline \multirow[t]{2}{*}{ Retinoic acid receptor } & Vit. A derivate & Mouse (cervical cancer) & $\uparrow$ Maturation of iMC & $(72)$ \\
\hline & & Human (lung, renal cancer) & MDSC depletion & $(73,74)$ \\
\hline \multirow[t]{2}{*}{ TLR3,5 or 9} & Agonists, siRNA, and TLR ligands & Mouse (breast, ovarian, and renal cancer) & $\downarrow M D S C$ & $(75-78)$ \\
\hline & & & 个TADC repolarization/maturation & \\
\hline Gr1 & Monoclonal Ab & Mouse (fibrosarcoma) & MDSC depletion & $(79)$ \\
\hline G-CSF & Monoclonal Ab & Mouse (several cancers) & $\begin{array}{l}\downarrow \text { Tumor-associated circulating myeloid } \\
\text { cells }\end{array}$ & (80) \\
\hline GM-CSF & Monoclonal Ab & Mouse (pancreas cancer) & $\downarrow$ Recruitment of Gr1+/CD11b+ & (81) \\
\hline IL6-R & Monoclonal Ab & Mouse (skin squamous cell cancer) & $\downarrow M D S C$ & $(82)$ \\
\hline $\mathrm{cKIT/SCF}$ & Monoclonal Ab & Mouse (colon carcinoma) & $\downarrow$ MDSC recruitment & (83) \\
\hline Bv8 & Monoclonal Ab & Mouse/human (several cancers) & $\downarrow$ MDSC recruitment and Expansion & (84) \\
\hline Carboxy-N-glycan & Monoclonal Ab & Mouse (blood, breast cancer) & $\downarrow \mathrm{MDSC}$ & (85) \\
\hline DR3 & Cytokine & Mouse (immature DC) & $\uparrow D C$ maturation & $(86)$ \\
\hline \multicolumn{5}{|c|}{ Intracellular tumor-infiltrating myeloid cell regulators } \\
\hline Several miRNAs & Nanoparticles & Mouse (ovarian, breast, and lung cancer) & $\uparrow$ TADC, TAM repolarization & $(87-90)$ \\
\hline \multirow[t]{2}{*}{ STAT3 } & Small molecules and siRNA & Mouse (melanoma and breast cancer) & १TADC, TAM/MDSC repolarization & $(91,92)$ \\
\hline & & Human (peripheral blood and several tumors) & $\downarrow$ im. suppr. of MDSC & $(93,94)$ \\
\hline Small Rho GTPases & Cytostatic drug & Mouse (lung cancer) & $\downarrow$ TADC formation & (95) \\
\hline Tyrosine Kinase & Small molecule & Human (renal cell carcinoma) & $\downarrow M D S C$ & $(96-99)$ \\
\hline \multirow[t]{2}{*}{ Legumain } & Cytostatic prodrug & Mouse (breast, lung cancer) & TAM depletion & $(100)$ \\
\hline & & Human (breast cancer) & $\downarrow$ im. suppr. of MDSC & \\
\hline PDE5 & Small molecule & Mouse (colon and breast cancer) & \im. suppr. of MDSC & $(101)$ \\
\hline IRF8 & Overexpression & Mouse (breast cancer) & $\downarrow$ MDSC accumulation & $(102)$ \\
\hline p50 NF-кB & siRNA & Mouse (melanoma, and pancreas cancer) & TAM repolarization & $(103)$ \\
\hline \multicolumn{5}{|c|}{ Extracellular suppressive molecules } \\
\hline Lactate dehydrogenase & Small molecule & Human (melanoma, and prostate cancer) & 个TADC repolarization/maturation & $(104)$ \\
\hline VEGF & Monoclonal Ab & Human (colon, lung, and breast cancer) & $\downarrow$ Immature DCs & $(105)$ \\
\hline $\operatorname{cox} 2$ & Small molecule & $\begin{array}{l}\text { Mouse (breast cancer) } \\
\text { Human (blood samples) }\end{array}$ & TAM repolarization & $(106,107)$ \\
\hline Fatty acid oxidation & Small molecule & Mouse (lung cancer) & $\downarrow$ im. suppr. of MDSC & $(94)$ \\
\hline Phosphatidylserine & Monoclonal Ab & Human (prostate cancer) & $\begin{array}{l}\text { TAM, MDSC depletion } \\
\text { †TAM, DC maturation }\end{array}$ & $(108)$ \\
\hline ROS & Small molecule & Mouse (colon and lung cancer) & $\downarrow$ im. suppr. of MDSC & $(109)$ \\
\hline \multicolumn{5}{|l|}{ Undefined targets } \\
\hline & Cytostatic drugs & $\begin{array}{l}\text { Mouse (bone marrow-derived MDSC, lung, } \\
\text { breast, and ovarian cancer) }\end{array}$ & $\begin{array}{l}\uparrow M D S C \text { diff. into DC } \\
\downarrow M D S C\end{array}$ & $(110-112)$ \\
\hline & Peptibodies & Mouse (thymoma) & MDSC depletion & $(113)$ \\
\hline & T. Gondii & Mouse (ovarian cancer) & 个immune stimulatory DC & $(114)$ \\
\hline & Histidine-rich glycoprotein & $\begin{array}{l}\text { Mouse (fibrosarcoma, breast, and pancreas } \\
\text { cancer) }\end{array}$ & TAM repolarization & $(115)$ \\
\hline
\end{tabular}

CSF, colony-stimulating factor; Ab, antibody; siRNA, small interfering RNA; CCL2/MCP-1, chemokine (C-C motif) ligand 2, monocyte chemotactic protein 1; Vit A, Vitamin A; TLR, toll-like receptor; G-CSF, granulocyte colony-stimulating factor; GM-CSF, granulocyte-macrophage colony-stimulating factor; cKIT/SCF, stem cell factor; DR3, death domaincontaining receptor-3; STAT3, signal transducer and activator of transcription 3; GTP, guanosine triphosphate; PDE5, phosphodiesterase type 5; IRF8, interferon regulatory factor 8; $N F-\kappa B$, nuclear factor $\kappa B$; VEGF, vascular endothelial growth factor; COX2, cyclo-oxygenase 2; ROS, reactive oxygen species. 
integrate, and finally converge into a few pathways, such as that of the signal transducer and activator of transcription (STAT) family and nuclear factor- $\mathrm{\kappa B}(\mathrm{NF}-\mathrm{\kappa B})$ to promote the protumor traits of different myeloid cell populations (54). Therefore, the plasticity of myeloid cells also challenges their categorization in subtypes based on phenotypic features. The observation that transcription factors and signature genes dictate their polarization and, therefore, function favors classifications based on stimulatory versus regulatory properties $(26,55)$. We believe that a simplified functional subdivision into myeloid stimulatory or regulatory cells gives a more perspicuous view on tumor-infiltrating myeloid cells. The scenario of shared phenotypical and functional traits driven by common transcriptional programs suggests that it is feasible to develop strategies to target different myeloid cell populations simultaneously and consequently therapeutically affect the protumor network established by cancer-associated myeloid cells.

\section{IMPLICATIONS FOR CANCER RESEARCH AND THERAPY}

One of the joint hallmarks of myeloid cells is their plasticity. This not only makes them susceptible to tumor-derived cues but also enables their manipulation and repolarization. Subsequently numerous studies have been conducted to either block their recruitment, deplete one or more suppressive myeloid cell subsets, and/or repolarize type 2 subsets to more tumoricidal type 1 myeloid cells (Table 1). From the studies listed in Table 1, we can draw some general conclusions.

First, therapeutics are administered systemically in most studies. However, for most if not all targets, this can result in major immunological deficits in the long run as the myeloid cell compartment is of paramount importance for maintenance of immunological homeostasis outside the tumor tissue. Therefore, we propose to focus on the development of therapeutic delivery systems that can restrict depletion and/or modulation of myeloid cells to the tumor niche.

Second, it is remarkable to see how most studies tend to focus on the modulation of "one particular subset" while most often "shared" receptors and regulators are targeted, such as CD11b and CSF-1 (68). Therefore, we believe that it would be more interesting to evaluate the behavior of the general intratumoral myeloid regulatory cells' state after therapy. For example, several groups that focus on TAMs have targeted CSF-1 and demonstrated a decrease in TAM recruitment, depletion, and/or M2 to $\mathrm{M} 1$ repolarization. Nevertheless, it would be more alluring to evaluate what CSF-1 blockage does with the shape of the general intratumoral myeloid regulatory cell population since CSF-1 is seen as one of the major attractants of "all" immature myeloid cells to the TME.

Third, instead of targeting "shared" phenotypic markers to block the recruitment or deplete a presumed tumor-infiltrating myeloid cell subset, we believe that targeting shared functional mechanisms can result in a higher chance that the whole TME can repolarize toward a myeloid stimulatory cell comprising milieu. Blockade of myeloid suppressive mechanisms can, therefore, be seen as a more "general" way to "target" the type 2 cancer-associate myeloid cell population without focusing on one particular subset. To that end, several strategies can be envisaged, such as blocking the VEGF and/or TGF- $\beta$ pathways $(19,96)$. Blocking the TGF- $\beta$ pathway is, to our current knowledge, one of the most appealing strategies to prevent polarization of type 2 tumor-infiltrating myeloid cells. This may have profound impact on the balance of M1-M2 TAMs and N1-N2 neutrophils and allow DC maturation. Blocking may also regulate the excessive recruitment of tumor-infiltrating myeloid cells and as such also decrease the amount of myeloid regulatory cells (19). Based on the lack of a unique definition for the tumor-infiltrating myeloid cell subset of interest, together with the observation that tumor-infiltrating myeloid cells play a multifaceted role and can exhibit tumoricidal capacities, it is reasonable to propose that re-polarization rather than their depletion will be substantially more beneficial (116). This is exemplified by a study where TGF- $\beta$ blockade resulted in a therapeutic antitumor response caused by an influx of repolarized oncolytic TANs that expressed high levels of pro-inflammatory cytokines, while neutrophil depletion significantly blunted these antitumor effects (29). Also CSF-1R inhibitors, TLR9 ligands combined with anti-IL10R antibodies or histidinerich glycoproteins resulted in an antitumor immune response caused by repolarization of the intratumoral myeloid regulatory cell population $(56,75,115)$.

Fourth, also non-tumoral, non-immunologic stromal cell populations, such as endothelial cells and fibroblasts, can have a major impact on the composition of the tumor-infiltrating myeloid cells, implicating that also these cell types are important to consider when envisaging modulation of the tumor-infiltrating myeloid cell composition (5). For example, targeting endothelial cells using a VEGF inhibitor resulted in decreased numbers of intratumoral MDSCs, while the depletion of cancer-associated fibroblasts, which express many immunosuppressive molecules, showed impaired tumor growth $(96,117)$.

Finally, although murine in vivo and human in vitro studies show great promise for tumor-infiltrating myeloid cell combating therapeutics, there is a current lack of clinical data regarding the effects of such treatments on the tumor-infiltrating myeloid cells and more specifically the regulatory myeloid cell versus stimulatory myeloid cell ratio in cancer patients (118).

Important to keep in mind is that everything in biology depends on homeostasis. Repolarizing myeloid regulatory cells to type 1 tumor-infiltrating myeloid cells will also lead to imbalance, probably increased antitumor immunity but most likely also an enhanced state of chronic inflammation that in turn can induce the recruitment of MDSCs again (118). However, it is presumed that also antitumor immunity is allowed to take course and as such elimination of tumor cells is promoted. Therefore, one can postulate that the inflammation will resolve as soon as all tumor cells are rejected and tissue repair is complete.

\section{CONCLUDING REMARKS}

In this perspective paper, we suggest that different myeloid cell populations evolve along with tumor progression, and that 
their phenotype and function is not as distinct as previously anticipated. This is supported by the plethora of papers on the subject of TAMs, TADCs, TANs, MDSCs, and how the plasticity of these cells allows them to acquire different activation states, even trans-differentiate into another cell subset, depending on the encountered factors. In the TME, a number of suppressive molecules trigger transcriptional programs that govern phenotypical and functional changes, endowing myeloid cells within the TME with a type 2 or immunosuppressive phenotype irrespective of the myeloid cell subset. We argue that the commonalities in phenotype and function provide an opportunity for therapeutic

\section{REFERENCES}

1. Coussens LM, Zitvogel L, Palucka AK. Neutralizing tumor-promoting chronic inflammation: a magic bullet? Science (2013) 339:286-91. doi:10.1126/science.1232227

2. Balkwill FR, Mantovani A. Cancer-related inflammation: common themes and therapeutic opportunities. Semin Cancer Biol (2012) 22:33-40. doi:10.1016/j.semcancer.2011.12.005

3. Didonato JA, Mercurio F, Karin M. NF- $\mathrm{BB}$ and the link between inflammation and cancer. Immunol Rev (2012) 246:379-400. doi:10.1111/ j.1600-065X.2012.01099.x

4. Crusz SM, Balkwill FR. Inflammation and cancer: advances and new agents. Nat Rev Clin Oncol (2015) 12(10):584-96. doi:10.1038/ nrclinonc. 2015.105

5. Turley SJ, Cremasco V, Astarita JL. Immunological hallmarks of stromal cells in the tumour microenvironment. Nat Rev Immunol (2015) 15:669-82. doi:10.1038/nri3902

6. Havel JJ, Chan TA. High-resolution genomic analysis: the tumor-immune interface comes into focus. Genome Biol (2015) 16:65. doi:10.1186/ s13059-015-0631-3

7. Jochems C, Schlom J. Tumor-infiltrating immune cells and prognosis: the potential link between conventional cancer therapy and immunity. Exp Biol Med (Maywood) (2011) 236:567-79. doi:10.1258/ebm.2011.011007

8. Tran Janco JM, Lamichhane P, Karyampudi L, Knutson KL. Tumor-infiltrating dendritic cells in cancer pathogenesis. J Immunol (2015) 194:2985-91. doi:10.4049/jimmunol.1403134

9. Lahmar Q, Keirsse J, Laoui D, Movahedi K, Van Overmeire E, Van Ginderachter JA. Tissue-resident versus monocyte-derived macrophages in the tumor microenvironment. Biochim Biophys Acta (2015) 1865(1):23-34. doi:10.1016/j.bbcan.2015.06.009

10. Messmer MN, Netherby CS, Banik D, Abrams SI. Tumor-induced myeloid dysfunction and its implications for cancer immunotherapy. Cancer Immunol Immunother (2015) 64:1-13. doi:10.1007/s00262-014-1639-3

11. Omatsu M, Kunimura T, Mikogami T, Shiokawa A, Nagai T, Masunaga A, et al. Difference in distribution profiles between CD163+ tumor-associated macrophages and S100+ dendritic cells in thymic epithelial tumors. Diagn Pathol (2014) 9:215. doi:10.1186/s13000-014-0215-7

12. Swartz MA, Iida N, Roberts EW, Sangaletti S, Wong MH, Yull FE, et al. Tumor microenvironment complexity: emerging roles in cancer therapy. Cancer Res (2012) 72:2473-80. doi:10.1158/0008-5472.CAN-12-0122

13. Gutkin DW, Shurin MR. Clinical evaluation of systemic and local immune responses in cancer: time for integration. Cancer Immunol Immunother (2014) 63:45-57. doi:10.1007/s00262-013-1480-0

14. Mantovani A, Sica A. Macrophages, innate immunity and cancer: balance, tolerance, and diversity. Curr Opin Immunol (2010) 22:231-7. doi:10.1016/j. coi.2010.01.009

15. Broz ML, Binnewies M, Boldajipour B, Nelson AE, Pollack JL, Erle DJ, et al. Dissecting the tumor myeloid compartment reveals rare activating antigen-presenting cells critical for T cell immunity. Cancer Cell (2014) 26:638-52. doi:10.1016/j.ccell.2014.09.007

16. Keskinov AA, Shurin MR. Myeloid regulatory cells in tumor spreading and metastasis. Immunobiology (2014) 220:236-42. doi:10.1016/j. imbio.2014.07.017 interventions that may concomitantly skew the myeloid cells to a type 1 state or as proposed to myeloid stimulatory cells.

\section{AUTHOR CONTRIBUTIONS}

YDV, AGR, CG, and KB contributed equally to the manuscript.

\section{FUNDING}

Research funded by Vlaamse Liga Tegen Kanker (Emmanuel van der Schueren) and OZR Vrije Universiteit Brussel.

17. Maenhout SK, Van Lint S, Emeagi PU, Thielemans K, Aerts JL. Enhanced suppressive capacity of tumor-infiltrating myeloid-derived suppressor cells compared with their peripheral counterparts. Int J Cancer (2014) 134:1077-90. doi:10.1002/ijc.28449

18. Laoui D, Van Overmeire E, De Baetselier P, Van Ginderachter JA, Raes G. Functional relationship between tumor-associated macrophages and macrophage colony-stimulating factor as contributors to cancer progression. Front Immunol (2014) 5:489. doi:10.3389/fimmu.2014.00489

19. Krstic J, Santibanez JF. Transforming growth factor-beta and matrix metalloproteinases: functional interactions in tumor stroma-infiltrating myeloid cells. ScientificWorldJournal (2014) 2014:521754. doi:10.1155/2014/ 521754

20. Senovilla L, Aranda F, Galluzzi L, Kroemer G. Impact of myeloid cells on the efficacy of anticancer chemotherapy. Curr Opin Immunol (2014) 30:24-31. doi:10.1016/j.coi.2014.05.009

21. Hettinger J, Richards DM, Hansson J, Barra MM, Joschko A-C, Krijgsveld J, et al. Origin of monocytes and macrophages in a committed progenitor. Nat Immunol (2013) 14:821-30. doi:10.1038/ni.2638

22. Onai N, Kurabayashi K, Hosoi-Amaike M, Toyama-Sorimachi N, Matsushima K, Inaba K, et al. A clonogenic progenitor with prominent plasmacytoid dendritic cell developmental potential. Immunity (2013) 38:943-57. doi:10.1016/j.immuni.2013.04.006

23. Onai N, Obata-Onai A, Schmid MA, Ohteki T, Jarrossay D, Manz MG. Identification of clonogenic common Flt3+M-CSFR+ plasmacytoid and conventional dendritic cell progenitors in mouse bone marrow. Nat Immunol (2007) 8:1207-16. doi:10.1038/ni1518

24. Ostrand-Rosenberg S. Tolerance and immune suppression in the tumor microenvironment. Cell Immunol (2015) 299:23-9. doi:10.1016/j. cellimm.2015.09.011

25. Lohela M, Casbon A-J, Olow A, Bonham L, Branstetter D, Weng N, et al. Intravital imaging reveals distinct responses of depleting dynamic tumor-associated macrophage and dendritic cell subpopulations. Proc Natl Acad Sci U S A (2014) 111:E5086-95. doi:10.1073/pnas.1419899111

26. van der Sluis TC, Sluijter M, van Duikeren S, West BL, Melief CJM, Arens $\mathrm{R}$, et al. Therapeutic peptide vaccine-induced CD8 T cells strongly modulate intratumoral macrophages required for tumor regression. Cancer Immunol Res (2015) 3(9):1042-51. doi:10.1158/2326-6066.CIR-15-0052

27. Ruffell B, Affara NI, Coussens LM. Differential macrophage programming in the tumor microenvironment. Trends Immunol (2012) 33:119-26. doi:10.1016/j.it.2011.12.001

28. Biswas SK, Mantovani A. Macrophage plasticity and interaction with lymphocyte subsets: cancer as a paradigm. Nat Immunol (2010) 11:889-96. doi:10.1038/ni.1937

29. Fridlender ZG, Sun J, Kim S, Kapoor V, Cheng G, Ling L, et al. Polarization of tumor-associated neutrophil phenotype by TGF-beta: "N1" versus "N2" TAN. Cancer Cell (2009) 16:183-94. doi:10.1016/j.ccr.2009.06.017

30. Gabrilovich DI, Ostrand-Rosenberg S, Bronte V. Coordinated regulation of myeloid cells by tumours. Nat Rev Immunol (2012) 12:253-68. doi:10.1038/ nri3175

31. Fridlender ZG, Sun J, Mishalian I, Singhal S, Cheng G, Kapoor V, et al. Transcriptomic analysis comparing tumor-associated neutrophils with granulocytic myeloid-derived suppressor cells and normal neutrophils. PLoS One (2012) 7:e31524. doi:10.1371/journal.pone.0031524 
32. Corzo CA, Condamine T, Lu L, Cotter MJ, Youn J-I, Cheng P, et al. HIF-1 $\alpha$ regulates function and differentiation of myeloid-derived suppressor cells in the tumor microenvironment. J Exp Med (2010) 207:2439-53. doi:10.1084/ jem.20100587

33. Narita Y, Wakita D, Ohkur T, Chamoto K, Nishimura T. Potential differentiation of tumor bearing mouse CD11b+Gr-1+ immature myeloid cells into both suppressor macrophages and immunostimulatory dendritic cells. Biomed Res (2009) 30:7-15. doi:10.2220/biomedres.30.7

34. Yang L, DeBusk LM, Fukuda K, Fingleton B, Green-Jarvis B, Shyr Y, et al. Expansion of myeloid immune suppressor Gr+CD11b+ cells in tumor-bearing host directly promotes tumor angiogenesis. Cancer Cell (2004) 6:409-21. doi:10.1016/j.ccr.2004.08.031

35. Nefedova Y, Nagaraj S, Rosenbauer A, Muro-Cacho C, Sebti SM, Gabrilovich DI. Regulation of dendritic cell differentiation and antitumor immune response in cancer by pharmacologic-selective inhibition of the janus-activated kinase 2/signal transducers and activators of transcription 3 pathway. Cancer Res (2005) 65:9525-35. doi:10.1158/0008-5472. CAN-05-0529

36. Diao J, Mikhailova A, Tang M, Gu H, Zhao J, Cattral MS. Immunostimulatory conventional dendritic cells evolve into regulatory macrophage-like cells. Blood (2012) 119:4919-27. doi:10.1182/blood-2011-11-392894

37. Guilliams M, Ginhoux F, Jakubzick C, Naik SH, Onai N, Schraml BU, et al. Dendritic cells, monocytes and macrophages: a unified nomenclature based on ontogeny. Nat Rev Immunol (2014) 14:571-8. doi:10.1038/nri3712

38. Talmadge JE, Gabrilovich DI. History of myeloid-derived suppressor cells. Nat Rev Cancer (2013) 13:739-52. doi:10.1038/nrc3581

39. Condamine T, Gabrilovich DI. Molecular mechanisms regulating myeloid-derived suppressor cell differentiation and function. Trends Immunol (2011) 32:19-25. doi:10.1016/j.it.2010.10.002

40. Grivennikov SI, Greten FR, Karin M. Immunity, inflammation, and cancer. Cell (2010) 140:883-99. doi:10.1016/j.cell.2010.01.025

41. Mills EL, O’Neill LA. Reprogramming mitochondrial metabolism in macrophages as an anti-inflammatory signal. Eur J Immunol (2016) 46:13-21. doi:10.1002/eji.201445427

42. Liu G, Bi Y, Shen B, Yang H, Zhang Y, Wang X, et al. SIRT1 limits the function and fate of myeloid-derived suppressor cells in tumors by orchestrating HIF$1 \alpha$-dependent glycolysis. Cancer Res (2014) 74:727-37. doi:10.1158/00085472.CAN-13-2584

43. Schouppe E, De Baetselier P, Van Ginderachter JA, Sarukhan A. Instruction of myeloid cells by the tumor microenvironment: open questions on the dynamics and plasticity of different tumor-associated myeloid cell populations. Oncoimmunology (2012) 1:1135-45. doi:10.4161/onci.21566

44. Chávez-Galán L, Olleros ML, Vesin D, Garcia I. Much more than M1 and M2 macrophages, there are also CD169(+) and TCR(+) macrophages. Front Immunol (2015) 6:263. doi:10.3389/fimmu.2015.00263

45. Helm O, Held-Feindt J, Grage-Griebenow E, Reiling N, Ungefroren H, Vogel I, et al. Tumor-associated macrophages exhibit pro- and anti-inflammatory properties by which they impact on pancreatic tumorigenesis. Int J Cancer (2014) 135:843-61. doi:10.1002/ijc.28736

46. Capece D, Fischietti M, Verzella D, Gaggiano A, Cicciarelli G, Tessitore A, et al. The inflammatory microenvironment in hepatocellular carcinoma: a pivotal role for tumor-associated macrophages. Biomed Res Int (2013) 2013:187204. doi:10.1155/2013/187204

47. Price JD, Tarbell KV. The role of dendritic cell subsets and innate immunity in the pathogenesis of type 1 diabetes and other autoimmune diseases. Front Immunol (2015) 6:288. doi:10.3389/fimmu.2015.00288

48. Ma Y, Shurin GV, Gutkin DW, Shurin MR. Tumor associated regulatory dendritic cells. Semin Cancer Biol (2012) 22:298-306. doi:10.1016/j. semcancer.2012.02.010

49. Van der Jeught K, Joe PT, Bialkowski L, Heirman C, Daszkiewicz L, Liechtenstein $\mathrm{T}$, et al. Intratumoral administration of mRNA encoding a fusokine consisting of IFN- $\beta$ and the ectodomain of the TGF- $\beta$ receptor II potentiates antitumor immunity. Oncotarget (2014) 5:10100-13. doi:10.18632/oncotarget.2463

50. Van Lint S, Renmans D, Broos K, Goethals L, Maenhout S, Benteyn D, et al. Intratumoral delivery of TriMix mRNA results in T-cell activation by cross-presenting dendritic cells. Cancer Immunol Res (2015) 4:146-56. doi:10.1158/2326-6066.CIR-15-0163
51. Manjili MH, Wang X-Y, Abrams S. Evolution of our understanding of myeloid regulatory cells: from MDSCs to Mregs. Front Immunol (2014) 5:303. doi:10.3389/fimmu.2014.00303

52. Reiman JM, Kmieciak M, Manjili MH, Knutson KL. Tumor immunoediting and immunosculpting pathways to cancer progression. Semin Cancer Biol (2007) 17:275-87. doi:10.1016/j.semcancer.2007.06.009

53. Beury DW, Parker KH, Nyandjo M, Sinha P, Carter KA, Ostrand-Rosenberg S. Cross-talk among myeloid-derived suppressor cells, macrophages, and tumor cells impacts the inflammatory milieu of solid tumors. J Leukoc Biol (2014) 96:1109-18. doi:10.1189/jlb.3A0414-210R

54. Sica A, Porta C, Morlacchi S, Banfi S, Strauss L, Rimoldi M, et al. Origin and functions of tumor-associated myeloid cells (TAMCs). Cancer Microenviron (2012) 5:133-49. doi:10.1007/s12307-011-0091-6

55. Gato M, Blanco-Luquin I, Zudaire M, de Morentin XM, Perez-Valderrama E, Zabaleta A, et al. Drafting the proteome landscape of myeloid-derived suppressor cells. Proteomics (2015) 16(2):367-78. doi:10.1002/pmic.201500229

56. Pyonteck SM, Akkari L, Schuhmacher AJ, Bowman RL, Sevenich L, Quail DF, et al. CSF-1R inhibition alters macrophage polarization and blocks glioma progression. Nat Med (2013) 19:1264-72. doi:10.1038/nm.3337

57. DeNardo DG, Brennan DJ, Rexhepaj E, Ruffell B, Shiao SL, Madden SF, et al. Leukocyte complexity predicts breast cancer survival and functionally regulates response to chemotherapy. Cancer Discov (2011) 1:54-67. doi:10.1158/2159-8274.CD-10-0028

58. Mok S, Koya RC, Tsui C, Xu J, Robert L, Wu L, et al. Inhibition of CSF-1 receptor improves the antitumor efficacy of adoptive cell transfer immunotherapy. Cancer Res (2014) 74:153-61. doi:10.1158/0008-5472.CAN-13-1816

59. Zhu Y, Knolhoff BL, Meyer MA, Nywening TM, West BL, Luo J, et al. CSF1/ CSF1R blockade reprograms tumor-infiltrating macrophages and improves response to $\mathrm{T}$ cell checkpoint immunotherapy in pancreatic cancer models. Cancer Res (2014) 74:1-22. doi:10.1158/0008-5472.CAN-13-3723

60. Priceman SJ, Sung JL, ShaposhnikZ, Burton JB, Torres-Collado AX, Moughon DL, et al. Targeting distinct tumor-infiltrating myeloid cells by inhibiting CSF-1 receptor: combating tumor evasion of antiangiogenic therapy. Blood (2010) 115:1461-71. doi:10.1182/blood-2009-08-237412

61. Kubota Y, Takubo K, Shimizu T, Ohno H, Kishi K, Shibuya M, et al. M-CSF inhibition selectively targets pathological angiogenesis and lymphangiogenesis. J Exp Med (2009) 206:1089-102. doi:10.1084/jem.20081605

62. Butowski N, Colman H, De Groot JF, Omuro AM, Nayak L, Wen PY, et al. Orally administered colony stimulating factor 1 receptor inhibitor PLX3397 in recurrent glioblastoma: an Ivy Foundation Early Phase Clinical Trials Consortium phase II study. Neuro Oncol (2016) 18:557-64. doi:10.1093/ neuonc/nov245

63. Manthey CL, Johnson DL, Illig CR, Tuman RW, Zhou Z, Baker JF, et al. JNJ-28312141, a novel orally active colony-stimulating factor-1 receptor/ FMS-related receptor tyrosine kinase-3 receptor tyrosine kinase inhibitor with potential utility in solid tumors, bone metastases, and acute myeloid leukemia. Mol Cancer Ther (2009) 8:3151-61. doi:10.1158/1535-7163. MCT-09-0255

64. Ries CH, Cannarile MA, Hoves S, Benz J, Wartha K, Runza V, et al. Targeting tumor-associated macrophages with anti-CSF-1R antibody reveals a strategy for cancer therapy. Cancer Cell (2014) 25:846-59. doi:10.1016/j. ccr.2014.05.016

65. Aharinejad S, Paulus P, Sioud M, Hofmann M, Zins K, Schäfer R, et al. Colony-stimulating factor-1 blockade by antisense oligonucleotides and small interfering RNAs suppresses growth of human mammary tumor xenografts in mice. Cancer Res (2004) 64:5378-84. doi:10.1158/0008-5472. CAN-04-0961

66. Abraham D, Zins K, Sioud M, Lucas T, Schäfer R, Stanley ER, et al. Stromal cell-derived CSF-1 blockade prolongs xenograft survival of CSF-1-negative neuroblastoma. Int J Cancer (2010) 126:1339-52. doi:10.1002/ijc.24859

67. Gazzaniga S, Bravo AI, Guglielmotti A, van Rooijen N, Maschi F, Vecchi A, et al. Targeting tumor-associated macrophages and inhibition of MCP-1 reduce angiogenesis and tumor growth in a human melanoma xenograft. J Invest Dermatol (2007) 127:2031-41. doi:10.1038/sj.jid.5700827

68. Khan ANH, Kolomeyevskaya N, Singel KL, Grimm MJ, Moysich KB, Daudi $\mathrm{S}$, et al. Targeting myeloid cells in the tumor microenvironment enhances vaccine efficacy in murine epithelial ovarian cancer. Oncotarget (2015) 6:11310-26. doi:10.18632/oncotarget.3597 
69. Tatsumi T, Huang J, Gooding WE, Gambotto A, Robbins PD, Vujanovic NL, et al. Intratumoral Delivery of Dendritic Cells Engineered to Secrete Both Interleukin (IL)-12 and IL-18 Effectively Treats Local and Distant Disease in Association with Broadly Reactive Tc1-type Immunity. Cancer Res (2003) 63:6378-86

70. Mangsbo SM, Broos S, Fletcher E, Veitonmäki N, Furebring C, Dahlén E, et al. The human agonistic CD40 antibody ADC-1013 eradicates bladder tumors and generates T-cell-dependent tumor immunity. Clin Cancer Res (2015) 21:1115-26. doi:10.1158/1078-0432.CCR-14-0913

71. Hunter TB, Alsarraj M, Gladue RP, Bedian V, Antonia SJ. An agonist antibody specific for $\mathrm{CD} 40$ induces dendritic cell maturation and promotes autologous anti-tumour T-cell responses in an in vitro mixed autologous tumour cell/lymph node cell model. Scand J Immunol (2007) 65:479-86. doi:10.1111/j.1365-3083.2007.01927.x

72. Kusmartsev S, Cheng F, Yu B, Nefedova Y, Sotomayor E, Lush R, et al. Alltrans-retinoic acid eliminates immature myeloid cells from tumor-bearing mice and improves the effect of vaccination. Cancer Res (2003) 63:4441-9.

73. Iclozan C, Antonia S, Chiappori A, Chen D-T, Gabrilovich D. Therapeutic regulation of myeloid-derived suppressor cells and immune response to cancer vaccine in patients with extensive stage small cell lung cancer. Cancer Immunol Immunother (2013) 62:909-18. doi:10.1007/s00262-013-1396-8

74. Mirza N, Fishman M, Fricke I, Dunn M, Neuger AM, Frost TJ, et al. All-transretinoic acid improves differentiation of myeloid cells and immune response in cancer patients. Cancer Res (2006) 66:9299-307. doi:10.1158/0008-5472. CAN-06-1690

75. Guiducci C, Vicari AP, Sangaletti S, Trinchieri G, Colombo MP. Redirecting in vivo elicited tumor infiltrating macrophages and dendritic cells towards tumor rejection. Cancer Res (2005) 65:3437-46. doi:10.1158/0008-5472. CAN-04-4262

76. Forghani P, Waller EK. Poly (I: C) modulates the immunosuppressive activity of myeloid-derived suppressor cells in a murine model of breast cancer. Breast Cancer Res Treat (2015) 153:21-30. doi:10.1007/s10549-015-3508-y

77. Cubillos-Ruiz JR, Engle X, Scarlett UK, Martinez D, Barber A, Elgueta R, et al. Polyethylenimine-based siRNA nanocomplexes reprogram tumor-associated dendritic cells via TLR5 to elicit therapeutic antitumor immunity. J Clin Invest (2009) 119:2231-44. doi:10.1172/JCI37716

78. James BR, Anderson KG, Brincks EL, Kucaba TA, Norian LA, Masopust D, et al. CpG-mediated modulation of MDSC contributes to the efficacy of Ad5TRAIL therapy against renal cell carcinoma. Cancer Immunol Immunother (2014) 63:1213-27. doi:10.1007/s00262-014-1598-8

79. Terabe M, Matsui S, Park J-M, Mamura M, Noben-Trauth N, Donaldson DD, et al. Transforming growth factor-beta production and myeloid cells are an effector mechanism through which CD1d-restricted $\mathrm{T}$ cells block cytotoxic $\mathrm{T}$ lymphocyte-mediated tumor immunosurveillance: abrogation prevents tumor recurrence. JExp Med (2003) 198:1741-52. doi:10.1084/ jem. 20022227

80. Shojaei F, Wu X, Qu X, Kowanetz M, Yu L, Tan M, et al. G-CSF-initiated myeloid cell mobilization and angiogenesis mediate tumor refractoriness to anti-VEGF therapy in mouse models. Proc Natl Acad Sci U S A (2009) 106:6742-7. doi:10.1073/pnas.0902280106

81. Bayne LJ, Beatty GL, Jhala N, Clark CE, Rhim AD, Stanger BZ, et al. Tumorderived granulocyte-macrophage colony-stimulating factor regulates myeloid inflammation and $\mathrm{T}$ cell immunity in pancreatic cancer. Cancer Cell (2012) 21:822-35. doi:10.1016/j.ccr.2012.04.025

82. Sumida K, Wakita D, Narita Y, Masuko K, Terada S, Watanabe K, et al. Anti-IL-6 receptor mAb eliminates myeloid-derived suppressor cells and inhibits tumor growth by enhancing T-cell responses. Eur J Immunol (2012) 42:2060-72. doi:10.1002/eji.201142335

83. Pan P-Y, Wang GX, Yin B, Ozao J, Ku T, Divino CM, et al. Reversion of immune tolerance in advanced malignancy: modulation of myeloid-derived suppressor cell development by blockade of stem-cell factor function. Blood (2008) 111:219-28. doi:10.1182/blood-2007-04-086835

84. Shojaei F, Wu X, Zhong C, Yu L, Liang X-H, Yao J, et al. Bv8 regulates myeloid-cell-dependent tumour angiogenesis. Nature (2007) 450:825-31. doi: 10.1038 /nature 06348

85. Sinha P, Okoro C, Foell D, Freeze HH, Ostrand-Rosenberg S, Srikrishna G. Proinflammatory S100 proteins regulate the accumulation of myeloid-derived suppressor cells. JImmunol (2008) 181:4666-75. doi:10.4049/ jimmunol.181.7.4666
86. Tian F, Grimaldo S, Fugita M, Cutts J, Vujanovic NL, Li L-Y. The endothelial cell-produced antiangiogenic cytokine vascular endothelial growth inhibitor induces dendritic cell maturation. J Immunol (2007) 179:3742-51. doi:10.4049/jimmunol.179.6.3742

87. Cubillos-Ruiz JR, Baird JR, Tesone AJ, Rutkowski MR, Scarlett UK, Camposeco-Jacobs AL, et al. Reprogramming tumor-associated dendritic cells in vivo using miRNA mimetics triggers protective immunity against ovarian cancer. Cancer Res (2012) 72:1683-93. doi:10.1158/0008-5472. CAN-11-3160

88. Yang J, Zhang Z, Chen C, Liu Y, Si Q, Chuang T-H, et al. MicroRNA-19a-3p inhibits breast cancer progression and metastasis by inducing macrophage polarization through downregulated expression of Fra-1 proto-oncogene. Oncogene (2014) 33:3014-23. doi:10.1038/onc.2013.258

89. Squadrito ML, Pucci F, Magri L, Moi D, Gilfillan GD, Ranghetti A, et al. miR-511-3p modulates genetic programs of tumor-associated macrophages. Cell Rep (2012) 1:141-54. doi:10.1016/j.celrep.2011.12.005

90. Cubillos-Ruiz JR, Silberman PC, Rutkowski MR, Chopra S, Perales-Puchalt A, Song M, et al. ER stress sensor XBP1 controls anti-tumor immunity by disrupting dendritic cell homeostasis. Cell (2015) 161:1527-38. doi:10.1016/j. cell.2015.05.025

91. Luo Z, Wang C, Yi H, Li P, Pan H, Liu L, et al. Nanovaccine loaded with poly I:C and STAT3 siRNA robustly elicits anti-tumor immune responses through modulating tumor-associated dendritic cells in vivo. Biomaterials (2015) 38:50-60. doi:10.1016/j.biomaterials.2014.10.050

92. Kodumudi KN, Woan K, Gilvary DL, Sahakian E, Wei S, Djeu JY. A novel chemoimmunomodulating property of docetaxel: suppression of myeloid-derived suppressor cells in tumor bearers. Clin Cancer Res (2010) 16:4583-94. doi:10.1158/1078-0432.CCR-10-0733

93. Vasquez-Dunddel D, Pan F, Zeng Q, Gorbounov M, Albesiano E, Fu J, et al. STAT3 regulates arginase-I in myeloid-derived suppressor cells from cancer patients. J Clin Invest (2013) 123:1580-9. doi:10.1172/JCI60083

94. Hossain DMS, Pal SK, Moreira D, Duttagupta P, Zhang Q, Won H, et al. TLR9-targeted STAT3 silencing abrogates immunosuppressive activity of myeloid-derived suppressor cells from prostate cancer patients. Clin Cancer Res (2015) 21:3771-82. doi:10.1158/1078-0432.CCR-14-3145

95. Zhong H, Gutkin DW, Han B, Ma Y, Keskinov AA, Shurin MR, et al. Origin and pharmacological modulation of tumor-associated regulatory dendritic cells. Int J Cancer (2014) 134:2633-45. doi:10.1002/ijc.28590

96. Ko JS, Zea AH, Rini BI, Ireland JL, Elson P, Cohen P, et al. Sunitinib mediates reversal of myeloid-derived suppressor cell accumulation in renal cell carcinoma patients. Clin Cancer Res (2009) 15:2148-57. doi:10.1158/1078-0432. CCR-08-1332

97. Ko JS, Rayman P, Ireland J, Swaidani S, Li G, Bunting KD, et al. Direct and differential suppression of myeloid-derived suppressor cell subsets by sunitinib is compartmentally constrained. Cancer Res (2010) 70:3526-36. doi:10.1158/0008-5472.CAN-09-3278

98. van Cruijsen H, van der Veldt AAM, Vroling L, Oosterhoff D, Broxterman HJ, Scheper RJ, et al. Sunitinib-induced myeloid lineage redistribution in renal cell cancer patients: $\mathrm{CD} 1 \mathrm{c}+$ dendritic cell frequency predicts progression-free survival. Clin Cancer Res (2008) 14:5884-92. doi:10.1158/10780432.CCR-08-0656

99. Huang D, Ding Y, Zhou M, Rini BI, Petillo D, Qian C-N, et al. Interleukin-8 mediates resistance to antiangiogenic agent sunitinib in renal cell carcinoma. Cancer Res (2010) 70:1063-71. doi:10.1158/0008-5472.CAN09-3965

100. Lin Y, Wei C, Liu Y, Qiu Y, Liu C, Guo F. Selective ablation of tumor-associated macrophages suppresses metastasis and angiogenesis. Cancer Sci (2013) 104:1217-25. doi:10.1111/cas.12202

101. Serafini P, Meckel K, Kelso M, Noonan K, Califano J, Koch W, et al. Phosphodiesterase- 5 inhibition augments endogenous antitumor immunity by reducing myeloid-derived suppressor cell function. JExp Med (2006) 203:2691-702. doi:10.1084/jem.20061104

102. Waight JD, Netherby C, Hensen ML, Miller A, Hu Q, Liu S, et al. Myeloidderived suppressor cell development is regulated by a STAT/IRF-8 axis. J Clin Invest (2013) 123:4464-78. doi:10.1172/JCI68189

103. Kono Y, Kawakami S, Higuchi Y, Yamashita F, Hashida M. In vitro evaluation of inhibitory effect of nuclear factor-kappaB activity by small interfering RNA on pro-tumor characteristics of M2-like macrophages. Biol Pharm Bull (2014) 37:137-44. doi:10.1248/bpb.b13-00659 
104. Gottfried E, Kunz-Schughart LA, Ebner S, Mueller-Klieser W, Hoves S, Andreesen R, et al. Tumor-derived lactic acid modulates dendritic cell activation and antigen expression. Blood (2006) 107:2013-21. doi:10.1182/ blood-2005-05-1795

105. Osada T, Chong G, Tansik R, Hong T, Spector N, Kumar R, et al. The effect of anti-VEGF therapy on immature myeloid cell and dendritic cells in cancer patients. Cancer Immunol Immunother (2008) 57:1115-24. doi:10.1007/ s00262-007-0441-x

106. Talmadge JE, Hood KC, Zobel LC, Shafer LR, Coles M, Toth B. Chemoprevention by cyclooxygenase- 2 inhibition reduces immature myeloid suppressor cell expansion. Int Immunopharmacol (2007) 7:140-51. doi:10.1016/j.intimp.2006.09.021

107. Na Y-R, Yoon Y-N, Son D-I, Seok S-H. Cyclooxygenase-2 inhibition blocks M2 macrophage differentiation and suppresses metastasis in murine breast cancer model. PLoS One (2013) 8:e63451. doi:10.1371/journal.pone.0063451

108. Yin Y, Huang X, Lynn KD, Thorpe PE. Phosphatidylserine-targeting antibody induces M1 macrophage polarization and promotes myeloid-derived suppressor cell differentiation. Cancer Immunol Res (2013) 1:256-68. doi:10.1158/2326-6066.CIR-13-0073

109. Nagaraj S, Youn J-I, Weber H, Iclozan C, Lu L, Cotter MJ, et al. Antiinflammatory triterpenoid blocks immune suppressive function of MDSCs and improves immune response in cancer. Clin Cancer Res (2010) 16:1812-23. doi:10.1158/1078-0432.CCR-09-3272

110. Michels T, Shurin GV, Naiditch H, Sevko A, Umansky V, Shurin MR. Paclitaxel promotes differentiation of myeloid-derived suppressor cells into dendritic cells in vitro in a TLR4-independent manner. J Immunotoxicol (2012) 9:292-300. doi:10.3109/1547691X.2011.642418

111. Suzuki E, Kapoor V, Jassar AS, Kaiser LR, Albelda SM. Gemcitabine selectively eliminates splenic Gr-1+/CD11b+ myeloid suppressor cells in tumor-bearing animals and enhances antitumor immune activity. Clin Cancer Res (2005) 11:6713-21. doi:10.1158/1078-0432.CCR-05-0883

112. Germano G, Frapolli R, Belgiovine C, Anselmo A, Pesce S, Liguori M, et al. Role of macrophage targeting in the antitumor activity of trabectedin. Cancer Cell (2013) 23:249-62. doi:10.1016/j.ccr.2013.01.008
113. Qin H, Lerman B, Sakamaki I, Wei G, Cha SC, Rao SS, et al. Generation of a new therapeutic peptide that depletes myeloid-derived suppressor cells in tumor-bearing mice. Nat Med (2014) 20:676-81. doi:10.1038/nm.3560

114. Baird JR, Fox BA, Sanders KL, Lizotte PH, Cubillos-Ruiz JR, Scarlett UK, et al. Avirulent Toxoplasma gondii generates therapeutic antitumor immunity by reversing immunosuppression in the ovarian cancer microenvironment. Cancer Res (2013) 73:3842-51. doi:10.1158/0008-5472. CAN-12-1974

115. Rolny C, Mazzone M, Tugues S, Laoui D, Johansson I, Coulon C, et al. HRG inhibits tumor growth and metastasis by inducing macrophage polarization and vessel normalization through downregulation of PlGF. Cancer Cell (2011) 19:31-44. doi:10.1016/j.ccr.2010.11.009

116. Klemm F, Joyce JA. Microenvironmental regulation of therapeutic response in cancer. Trends Cell Biol (2015) 25:198-213. doi:10.1016/j. tcb.2014.11.006

117. Kraman M, Bambrough PJ, Arnold JN, Roberts EW, Magiera L, Jones JO, et al. Suppression of antitumor immunity by stromal cells expressing fibroblast activation protein-alpha. Science (2010) 330:827-30. doi:10.1126/ science. 1195300

118. Meirow Y, Kanterman J, Baniyash M. Paving the road to tumor development and spreading: myeloid-derived suppressor cells are ruling the fate. Front Immunol (2015) 6:523. doi:10.3389/fimmu.2015.00523

Conflict of Interest Statement: The authors declare that the research was conducted in the absence of any commercial or financial relationships that could be construed as a potential conflict of interest.

Copyright (c) 2016 De Vlaeminck, González-Rascón, Goyvaerts and Breckpot. This is an open-access article distributed under the terms of the Creative Commons Attribution License (CC BY). The use, distribution or reproduction in other forums is permitted, provided the original author(s) or licensor are credited and that the original publication in this journal is cited, in accordance with accepted academic practice. No use, distribution or reproduction is permitted which does not comply with these terms. 